\title{
Sociedad Plural, Escuela y Cooperativismo *
}

\author{
PluRal Society, SChOol and Cooperativisu
}

\author{
Manuel Silva Águila \\ Especialista en Currículo \\ Universidad de Chile \\ Ignacio Carrera Pinto 1045, Ñuñoa, Santiago \\ msilvaag@uchile.cl
}

Recibido: 22 de noviembre, 2007. Aceptado: 3 de diciembre, 2007

\begin{abstract}
Resumen: Esta presentación en el Seminario se refiere a la búsqueda de establecer interconexiones entre la sociedad actual, de naturaleza plural; la denominada segunda modernidad, como contexto histórico; la escuela como espacio de lo público; la nostalgia de la comunidad que agobia a los entes virtuales y el espíritu cooperativo que puede aglutinar y dar sentido a la existencia actual.

Palabras clave: cooperativismo, capital social, comunidad, escuela, sociedad.
\end{abstract}

Abstract: This presentation in the Seminar refers to the search of interconnections between: society at present, of a plural nature; the so-called second modernity, as a historic context; the school, as a public space; the nostalgia of the community, which overwhelms the virtual entities; and the cooperative spirit that can agglutinate and give sense to existence nowadays.

Keywords: cooperativism, social capital, community, school, society.

\section{INTRODUCCIÓN}

La sociedad actual se caracteriza por una pérdida progresiva de lazos de sociabilidad. Las relaciones virtuales que se desarrollan en el marco de la red Internet dificultan cada vez más los contactos directos y el despliegue de interacciones afectivas tan necesarias desde el punto de vista del desarrollo humano integral. Se ha pasado de la fisicidad de las relaciones humanas a la virtualidad de las mismas (Pérez, 2000).

El proceso de modernización conduce a un progresivo deterioro de los vínculos al interior de las comunidades. Así, el estudioso Bauman (1999) destaca el estado de inseguridad, incertidumbre y desprotección que inevitablemente conlleva la extensión de los mecanismos de mercado. Esta experiencia se vive en soledad, y aisla y divide a las personas entre sí. Al mismo tiempo plantea que estos procesos engendran un enfriamiento de las

\footnotetext{
* Presentada en el X Seminario Internacional Red UNIRCOOP, LA INTERCOOPERACIÓN: DE LA TEORÍA A LA PRÁCTICA, Copan Ruinas, Honduras, 2 de noviembre de 2006.
} 
relaciones humanas. Las relaciones interpersonales, los contactos cara a cara se debilitan y distancian, con lo que aumenta la desconfianza.

Este fenómeno alcanza a la familia, en donde los vínculos son cada vez menos exigentes. La aceleración del tiempo histórico y los crecientes compromisos laborales que absorben cada vez más tiempo a los progenitores, hace que los momentos de estar juntos compartiendo espacios y tiempos de conversación y afecto se distancien y sean ocupados por artefactos que distancian las comunicaciones interpersonales directas tales como la televisión, el chat o el celular.

También se observa un deterioro de las relaciones de amistad, porque éstas no son capaces de aportar ayuda frente a los nuevos problemas que agobian a los individuos.

En esta misma dirección Bauman afirma que el mundo moderno se basa en el trabajo, entendido como vocación y misión en la vida. No obstante, con la irrupción de lo que denomina segunda modernidad, este fundamento colapsa. Así, el trabajo deja de ser una forma de integración estable y válida, y lo que emerge es lo que Bauman denomina un orden líquido.

De esta forma, los comienzos de este nuevo siglo nos exhiben una flexibilización constante de las estructuras, lo que conduce a que las paredes de las mismas dejen de ser sólidas, permanentes, inmóviles. Los límites se vuelven difusos y dejan de ser fuentes de seguridad. Se pierde aquel orden que permitía moverse en un mundo establecido, claro y sólido; reflejo de una sociedad fundada en el orden racional propio del espíritu de la modernidad (Touraine, 1994).

Todo lo expuesto anteriormente hace nacer un sentimiento generalizado de desarraigo, donde los problemas se sufren aisladamente, y agresiones que asedian a los individuos se viven como asuntos sólo personales.

De acuerdo con el pensamiento del sociólogo Eugenio Tironi (2005), planteamos que, frente a esta realidad que constriñe a los habitantes de la sociedad actual, aflora una emoción que mira con trémula emoción el pasado. En palabras del autor, "el sentimiento de nostalgia hacia la comunidad se explica en que actualmente se extraña la sensación de seguridad que ella otorga, lo cual es un requisito fundamental para una vida feliz. Inmersos en un mundo fluido, líquido, desregulado, flexible, competitivo y endémicamente inseguro, donde las fuentes de inseguridad están escondidas y no pueden ser localizadas en un mapa, la inseguridad afecta a todos por igual. En un mundo 
individualista y privatizado como el actual, cada cual sufre esta angustia aisladamente. La seguridad se ha transformado en un problema personal que cada uno busca resolver por sí mismo. Pero todos necesitan obtener mayor control sobre las incertidumbres que les atañen, y la gran mayoría aspira a tenerlo colectiva o comunitariamente, toda vez que el estado moderno es incapaz de responder a esta demanda. Así, la comunidad es mirada como un refugio ante la inseguridad del mundo moderno" (pp. 65-66).

\section{SOCIEDAD PLURAL Y ESCUELA}

La búsqueda de los vínculos entre sociedad y escuela proveen antecedentes substantivos a la hora de hurgar en la indagación de los sentidos y significados de la educación escolar en un mundo complejo, distante, casi ajeno.

Si examinamos más finamente los elementos que conforman el contexto social a nivel internacional y nacional, podemos distinguir algunos que tienen relevancia central:

La diversidad étnica y cultural. Las sociedades actuales se caracterizan por una elevada dinámica demográfica, que multiplica los procesos de emigración e inmigración. De esta forma las sociedades contemporáneas se transforman en verdaderos mosaicos que reflejan la heterogeneidad cultural, religiosa, lingüística, nacional. El paisaje urbano refleja este encuentro cotidiano de múltiples raigambres.

Cambios en los valores y la moralidad. El influjo masivo de los medios de comunicación hace que sus mensajes exporten modelos de convivencia que muchas veces entran en colisión con costumbres arraigadas en las comunidades nacionales. Estos impactan directamente en las jóvenes generaciones quienes protagonizan cambios sutiles, graduales pero profundos en el tejido de las relaciones sociales. Ello genera roces y tensiones entre generaciones que a veces no encuentran puntos de contacto y de mutua comprensión.

La revolución microelectrónica. La informática y las telecomunicaciones han transformado cualitativamente los procesos de intercambio de bienes físicos y simbólicos. También los procesos de enseñanza y aprendizaje. La capacidad de los nuevos dispositivos para almacenar, procesar y transferir información y conocimiento genera nuevos espacios virtuales que se transforman en escenarios de las nuevas formas de los complejos procesos de transmisión cultural. Los notebooks, los MP3, los MP4, los IPOD, los móviles han modificado nuestras formas de existencia y de comunicación. 
El medio a mbiente. Producto de la visión de la modernidad respecto a la relación entre el individuo y el entorno, inspirada en Bacon, que atribuía a la ciencia un papel central en la generación de conocimientos acerca de los fenómenos naturales y físicos, se otorgó a aquellos un carácter pragmático. De esta forma el conocimiento era considerado útil para transformar la naturaleza en beneficio de los individuos. Ello ha derivado, en una interpretación inicial, al deterioro progresivo del entorno, que se expresa en el cambio climático, la lluvia ácida, el calentamiento global de la atmósfera y los océanos, la deforestación de gran parte de las superficies boscosas, la contaminación. Esto impacta centralmente en la salud física y mental de los ciudadanos que deben sufrir los efectos del progreso, ilusión de la modernidad.

La familia. Como apreciábamos anteriormente, esta institución se ve asediada y debilitada por las nuevas condiciones que impone la nueva economía al trabajo. Este adquiere una condición de incertidumbre y de demandas crecientes de tiempo abocado a las tareas específicas. Ello conduce a la conformación de diversos tipos de familia que ofrecen un horizonte de inestabilidad a los hijos. Los roles de entregar afecto y apoyo se comienzan a diluir.

La interdependencia global. Los intercambios entre países que en un comienzo tuvieron un carácter comercial, progresivamente se abrieron a otros campos como el político, el científico, el económico y finalmente el cultural. Vivimos en lo que McLuhan denominó aldea global. La noción de que todos necesitamos de todos está presente en esta perspectiva, lo que abre un espacio para deliberar acerca de los contenidos de los intercambios y la relación que se establece entre globalización y estados nacionales, entre homogeneización planetaria e identidad, entre volatibilidad y raigambre.

Cambios en el mundo del trabajo. El traslado histórico desde la sociedad industrial a la sociedad de la información (Castells, 1997) está implicando nuevas relaciones contractuales, empleos más inestables y la necesidad de poseer un conjunto de competencias que les habiliten para una inserción funcional a las nuevas demandas que se desprenden de las nuevas tecnologías y los nuevos puestos de trabajo tanto físicos como virtuales.

Falta de propósitos y significados. Ello porque en la realidad actual se percibe una aguda falta de proyectos colectivos que convoquen, aglutinen y comprometan al conjunto de la población. Hoy es el sitio de los proyectos personales. Se respira un vacío respecto de contenidos que añadan sentido a múltiples acciones. Tal vez el fútbol sea uno de los escasos fenómenos que logra reunir en un entusiasmo colectivo. 
Crimen y violencia. La vida cotidiana es sacudida con informaciones que despliegan amenazas a las normas de convivencia compartidas. Las manifestaciones de agresividad y de atentados al bien común reflejan un desasosiego y una falta de apego a lo establecido. Estas expresiones se viven tanto a nivel macrosocial como a nivel microsocial (barrio, escuela, trabajo).

Igualdad de derechos. La presión por el reconocimiento de los múltiples grupos de heterogénea proveniencia al interior de las sociedades es un signo del presente. Ello ha permitido que progresivamente diversos grupos accedan al ejercicio de derechos que antes les eran restringidos.

El conjunto de estos elementos genera una presión a la escuela, institución que debe entrar en diálogo, y atender los múltiples requerimientos del contexto descrito.

Si examinamos los retos de la escuela en el momento actual, observaremos que ésta asume una misión moral. Así se inscribe el educador canadiense Michael Fullan (2002) quien, citando a Goodlad, define cuatro imperativos morales:

\section{- Facilitar una enculturación crítica:}

La escuela es la única institución de nuestra nación que se encarga específicamente de la enculturación de los jóvenes en una democracia política. Las escuelas son las protagonistas principales del desarrollo de personas educadas que adquieren un concepto de la verdad, la belleza y la justicia, con el que poder juzgar sus propias virtudes e imperfecciones y las de la sociedad. Esta es una responsabilidad moral.

- Proporcionar acceso al conocimiento:

La escuela es la única institución de nuestra sociedad encargada específicamente de proporcionar a los jóvenes un contacto disciplinado con todas las materias del diálogo humano: el mundo concebido como un sistema físico y biológico, sistema de valores y creencias, sistemas de comunicación, los sistemas sociales, políticos y económicos que componen la aldea global, y la propia especie humana...(los profesores) diligentes deben asegurarse de que ninguna actitud, creencia o práctica impida a los alumnos tener acceso al conocimiento necesario.

- Construir una conexión efectiva profesor-alumno:

La responsabilidad moral de los educadores se hace especialmente evidente en el momento en que se cruzan las vidas de los profesores con las de los alumnos. La epistemología de la educación debe englobar 
una pedagogía que vaya más allá de la mecánica de la enseñanza. Debe combinar principios de enseñanza generalizables, una instrucción específica de materias, sensibilidad hacia los siempre omnipresentes potenciales y cualidades humanos.

\section{- Tener una buena dirección:}

Si las escuelas tienen que llegar a ser instituciones sensibles y en renovación, su profesorado debe comprometerse resueltamente en el proceso de renovación.

Frente a estos imperativos morales podemos hacer un ejercicio de diálogo entre la escuela y los elementos del contexto que la asedian y buscan en ella una respuesta y una atención a sus demandas sentidas.

En esta dirección, la diversidad étnica y cultural presenta un desafío mayor a la escuela tanto en relación a su estructura organizacional como a las formas que adquiere el currículo para atender con el respeto que corresponde a un alumnado de heterogéneo origen. Las adecuaciones de los contenidos, las metodologías, las formas de evaluación son asuntos prioritarios de la agenda escolar actual.

En el mismo sentido se debe hacer cargo del examen crítico de las múltiples fuentes del entorno que influyen a través de modelos de conducta de proveniencias culturales ajenas que tienden a debilitar formas de convivencia arraigadas y sentidas por la comunidad. Estas afectan a los valores y la moralidad que estructura la vida de la comunidad.

La revolución microelectrónica y sus artefactos aportan nuevos medios de enseñanza y aprendizaje. La escuela debe buscar las formas adecuadas para un uso intensivo de los mismos (Area, 2001) porque las jóvenes generaciones tienen una familiaridad natural con estos elementos. Su uso los motiva y capta su atención.

Respecto del medio ambiente, engendrar actitudes proactivas y de anticipación en las jóvenes generaciones es una tarea inmediata. La escuela debe proveerles de competencias, conocimientos y valores que orienten su mirada y su acción frente a un medio ambiente sano y preservarlo para las generaciones que vienen.

En el mismo plano se sitúan sus acciones frente a la familia, que toma cierta distancia de sus responsabilidades escolares; la interdependencia global, que exige el aprendizaje de capacidades tales como aprender a aprender y 
aprender a emprender; los cambios en el mundo del trabajo que exigen una mirada nueva frente a un futuro incierto y a un orden inestable y volátil; la falta de propósitos y significados, que angustia por lo inasible de los marcos de referencia orientadores de la existencia; el crimen y la violencia se inhiben si encontramos un orden social más justo y con mejor calidad de vida para todos; y la igualdad de derechos encuentra su espacio en un mundo donde anida la apertura y la comprensión, actitudes que se aprenden.

\section{SOCIEDAD PLURAL, ESCUELA Y COOPERATIVISMO}

La idea cooperativa se vincula con tareas entre personas que tienen contacto directo, cara a cara, y que se involucran en esfuerzos cuyos fines van en beneficio del grupo y de la comunidad. Esto rompe con la dirección que impone la segunda modernidad.

$\mathrm{Al}$ interior del grupo cooperativo es posible construir y amplificar el denominado capital social. Éste se entiende como el conjunto de conexiones sociales entre individuos, que proveen beneficios tanto a sus portadores cuyas vidas particulares se vuelven más productivas y adquieren mayor valor al estar conectadas con otras a través de redes y vínculos sociales- como a la sociedad en su conjunto, la cual se beneficia de estas externalidades, como son la formación de redes portadoras de normas de conducta, obligaciones mutuas y reciprocidad (Putnam, 2000).

El capital social supone estar inserto en una estructura de asociación, expectativas, reciprocidad y mutualidad con otras personas. Pero a diferencia del capital económico, que está en el patrimonio de cada individuo, "éste se localiza en la estructura de relaciones sociales. Para poseer capital social una persona debe estar relacionada con otros, y son éstos los que se constituyen en la fuente de su ventaja, de su valor" (Tironi, 2005, p. 59).

En este momento podemos tejer puntos de intersección entre los ámbitos de esta sociedad plural, producto de la segunda modernidad, que condena a sus ciudadanos a la soledad, al desarraigo, a la incertidumbre, al enfriamiento de las relaciones humanas, a la nostalgia de la comunidad; la escuela, que tiene imperativos morales y cuya misión es contribuir a la integración social y a la movilidad social, a instalar redes de conversación y de convivencia que enseñan a vivir y a convivir en una sociedad plural; y el cooperativismo, que tiene en su esencia la idea del compartir, del asumir tareas colectivas vinculadas al bien del grupo y de la comunidad. 
Es posible pensar, y soñar, que el espíritu cooperativo, instalado en la escuela, puede contribuir a humanizar la convivencia, a llenar de sentido las conversaciones y los esfuerzos, a recuperar en lo micro, como anticipación, un mundo donde las personas se encuentran y construyen un futuro mejor, más solidario, fraterno y justo.

\section{REFERENCIAS BIBLIOGRÁFICAS}

Area, M., 2001

Castells, M., 1997

Bauman, Z., 1999

Fullan, M., 2002

Perez, J. M., 2000

Putnam, R., 2000

Tironi, E., 2005

Touraine, A., 1994
Educar en la sociedad de la información. Bilbao. Desclée De Brouwer.

La era de la información. La sociedad red. Madrid. Alianza Editorial.

Globalización: las consecuencias humanas. Buenos Aires. Fondo de Cultura Económica.

Las fuerzas del cambio. Explorando las profundidades de la Reforma Educativa. Madrid. Akal.

Comunicación y educación en la sociedad de la información. Barcelona. Paidos.

Bowling alone: the collapse and revival of American Community. New York: Simon \& Schuster.

El sueño chileno. Comunidad, familia y nación en el bicentenario. Santiago. Taurus.

Crítica de la modernidad. Buenos Aires. Fondo de Cultura Económica. 